\title{
La soledad del manager como definición de la serie Carvalho
}

\author{
JOSE V. SAVAL
}

Como cuenta una anécdota, después de un distendido almuerzo entre amigos en Casa Leopoldo, le comentaron a Manuel Vázquez Montalbán, entre bromas, que Carvalho, debido a sus coincidencias con su creador debería ser bajito y gordo, este respondió que no, que él tenía en mente un actor como Harvey Keitel. Su deseo se cumplió, en mayor o menor medida, cuando el actor norteamericano protagonizó The Galíndez Files (estrenada en España con el título de El misterio Galíndez, dirigida por el reputado cineasta Gerardo Herrero en 2003. La coincidencia resulta interesante, aunque cabe añadir que cuando se decidió llevar a Carvalho al comic se optó por un rostro que tiene grandes parecidos con Ben Gazzara, otro de los actores que Vázquez Montalbán consideraba afín físicamente al personaje de su creación.

Una de las diversas aportaciones de La soledad del manager, tercera novela de la serie Carvalho, reside en el comentario político de la realidad circundante, una voluntad de estudio de formas de los distintos grupos sociales, como señala José María Izquierdo: "Las obras de Carvalho son verdaderas fuentes históricas para entender las recientes historias de España y Barcelona, recuperar la memoria histórica de la izquierda y esbozar un modelo de ethos democrático" (Izquierdo 96). Para José Colmeiro es una de las claves de la serie Carvalho y en su opinión Manuel Vázquez Montalbán emplea el género de la novela policiaca: "para hacer su crónica de la vida colectiva española durante y después de la transición democrática" (Colmeiro 171). Mari Paz Balibrea ha manifestado al respecto que:

A través de la investigación y el esclarecimiento de las identidades de los personajes de estas dos novelas [La soledad del mánager y Los mares del Sur] se desvela un discurso político de acusación a la ex-izquierda crecientemente hegemónica de la España democrática (Balibrea 90).

En la opinión de Paco Camarasa:

Vázquez Montalbán utiliza los códigos de la novela negra, que no policial, más clásica, lo que le permite caminar por la parte oscura en la que la política y el delito se relacionan. Llegar allí donde como periodista no podía llegar sin acarrear la suspensión de la publicación, como tantas veces le ocurriera (Camarasa 13). 
Con respecto a la novela que es objeto de este estudio, Michael Eaude considera que:

La soledad del manager fue la primera novela de la serie que se publicaría tras la muerte de Franco. En este libro, las descripciones relativas al sexo y a cagar son detalladas y desenfadadas, las cuestiones políticas agradablemente explícitas. Aquí Vázquez Montalbán puede expresar con claridad lo que solo pudo insinuar en Tatuaje. El criminal es con toda rotundidad la multinacional norteamericana Petnay; la persona responsable del asesinato es un prominente de la clase capitalista (Eaude 77).

Probablemente la desaparación de los componentes politicorepresivos de la dictadura consolidará la serie, esta vez, totalmente libre de ataduras, permitiendo a su autor incluir los elementos más característicos de la serie y por lo tanto de conformar su definitivo formato y definición.

La trama es como sigue: un mánager o ejecutivo, al cual Pepe Carvalho había conocido en los Estados Unidos años antes, es hallado muerto en los alrededores de Barcelona con unas bragas de mujer en el bolsillo. El mánager tenía fama de mujeriego desenfrenado, suficiente para que la policía archive el caso: un cliente molesto ha sido eliminado por el proxeneta de una prostituta acosada. Pero el agudo Carvalho, tras haber sido contratado por la viuda para esclarecer el caso, no se conforma con la versión oficial y acabará descubriendo una realidad todavía más incómoda. La soledad del mánager termina esclareciendo las siniestras maquinaciones de una multinacional que financia grupos ultraderechistas que pretenden desestabilizar la nueva democracia española. Finalmente, con esta novela habrá encontrado el tono adecuado y la fórmula mágica de la serie.

La soledad del manager dentro de la serie Carvalho, en su tercera entrega, resulta ser la novela donde se establece el personaje de manera definitiva, asimismo como las bases de toda la serie (aunque con algunas variantes posteriores). La serie se consolidaba a través de su personaje principal, así como los personajes secundarios -Biscuter, Charo y Bromuro- que le acompañarán, por un largo trecho y en el caso de Biscuter más allá del final de toda la serie.

El cine policiaco resultará predominante en la caracterización del personaje y de la serie en general. Vázquez Montalbán siempre subrayaba su desconocimiento de la tradición del "hard boiled novel" norteamericano y probablemente el personaje y la concepción de la serie, a partir de 
La soledad del manager, tengan mayores vinculaciones con la tradición cinematográfica y televisiva que con la tradición literaria. También en este texto carvalhiano encontramos pistas sobre futuras entregas de la serie, cuando comenta la futura trama de Los mares del Sur, lo que se iba a convertir en, hasta cierto punto, habitual en la serie. También en $L a$ soledad del manager se impone de manera definitiva la receta carvalhiana como también la quema de libros y los elementos autobiográficos, o meras coincidencias, del autor en conexión con su personaje principal.

Como comentó el autor desde el libro-entrevista preparado por Quim Aranda en Què pensa Manuel Vázquez Montalbán, este texto sentaría las bases de la serie carvalhiana: "tenia ja la formula que pretenia: l'esbós del que podria ser la sèrie Carvalho. Hi havia arribat d'una manera molt més sòlida, molt més segura, que després d'haver acabat Tatuaje" (Aranda 65). En palabras del propio autor desde Geometrías de la memoria, libro entrevista propiciado por Georges Tyras:

La segunda novela que escribí, que sería la tercera del ciclo contando Yo mate a Kennedy, fue La soledad del manager. La idea surgió de un viaje que hice a los Estados Unidos con un grupo de amigos. Uno de ellos reunía unas características muy concretas - es el personaje al que se encuentra asesinado, en la novela - y un día de repente, me dijo: "Tienes delante de ti al manager de una multinacional"; con el mismo tono de guasa añadió: "Tú no lo entiendes porque vosotros, los marxistas, no podéis entender esto, no podéis entender la soledad del manager". Me gustó muchísimo esa frase. A partir de eso y de lo que habíamos hablado durante el viaje construí la trama. Más tarde, he sido muy consciente de que esto constituía las fases del aprendizaje. Tatuaje y, sobre todo, La soledad del manager me enseñaron a enfrentarme a un tipo de escritura que hasta entonces no había ensayado. Por añadidura la familia de Carvalho aumenta, el personaje necesita otros puntos de apoyo para resultar verosímil, para tener un mundo propio. Proyecto a Carvalho como una serie, cuyos títulos y contenidos empiezó a comunicar a la prensa (Tyras 102).

Especialmente en el artículo a toda página que publicaba en Interviu, que Francesc Salgado ha estudiado abriendo una interesante línea de investigación, donde comentaba e ilustraba la deriva del, entonces, nuevo personaje. Resulta muy interesante la investigación llevada a cabo por Salgado puesto que ha puesto de manifiesto el elemento experimental de la creación definitiva del detective más famoso de la transición. El personaje se fue desarrollando desde las páginas de la publicación semanal: 
El personaje de Carvalho y algunos secundarios como Charo, Biscuter o Bromuro se perfilan en unos articulos que se dedican en realidad a comentar la situación política en la que el detective avezado desvela a su vecino cuál es la realidad profunda del país. (...) Carvalho desarrolla en las páginas de Interviu durante 1977 parte del carácter desapegado, transgresor y lúcido que le caracterizará a lo largo de 27 novelas. La serie se llama "El idiota en familia", aparecen 52 articulos y concluye a finales de año, precisamente cuando se publica la siguiente novela de la serie La soledad del manager (Salgado 16).

Un buen ejemplo, conectado con la novela en cuestión, es el artículo "La Internacional fascista", aparecido el 3 de febrero de 1977 (Salgado 144-147), donde Carvalho explica a su vecino, un tal Vázquez (interesante coincidencia) las tácticas de la Cía, y su posible influencia en la política española. En el caso de La soledad del manager, la acción se inicia cuando Carvalho todavía es agente de la Cía. El caso empieza a desarrollarse en un doble plano temporal, conectando la acción de la investigación con el pasado donde casualmente el detective conoció al personaje asesinado.

Una de las claves de esta novela, como ya se ha comentado anteriormente, es la aparición de los personajes secundarios, para apoyar los diferentes puntos de vista y aumentar la familia carvalhiana. Otro buen ejemplo es el artículo "La tortilla de Biscúter" aparecido en Interviu con fecha de 6 de enero de 1977 sobre el personaje secundario de la serie. La única variante de que en el artículo periodístico, Biscuter procede del Principado de Mónaco y no del Principado de Andorra como era el caso real del personaje que el autor conoció durante su reclusión en la cárcel de Lérida (Aranda 42 y Saval 2014 60-61). En La soledad del manager será el primero del triunvirato de acompañantes de Carvalho en aparecer y ser presentado.

El autor describe al ayudante de Carvalho en la novela de la siguiente manera:

Al cuidado del despacho estaba Biscuter, ex compañero de cárcel de Carvalho. El detective nunca había sabido su nombre. Durante años de vez en cuando se decía: He de preguntarle como se llama. Pero el uso continuado de Biscuter cumplía la función y le desmemoriaba. Obseso con los coches ajenos, Biscuter había sido culito de cárcel durante quince años de larga adolescencia (Vázquez Montalbán 23-24). 
A esta descripción seguirá la de Bromuro (Vázquez Montalbán 2627) menos directa porque se hace mediante el diálogo que mantienen sobre el caso que tiene el detective entre manos y sobre la vida en general. Posteriormente tambien aparecerá Charo aunque también describiéndola mediante sus acciones más que de una manera directa como había hecho con Biscuter (Vázquez Montalbán 125). En esta narración también, hacia el final, Carvalho manifiesta su relación e interés por estos tres personajes al comentar la posible redacción de su testamento (Vázquez Montalbán 148), donde se preocupa de dejar sus ahorros y el inmueble de su propiedad en el vecindario de Vallvidrera en herencia a Charo y Biscuter y su bodega al Bromuro. Después de todo, los amigos en casa Leopoldo de Vázquez Montalbán, como comentaba la anécdota, no andaban tan desencaminados ya que Biscuter había compartido días de prisión con el autor y en la novela decide legar su propiedad, o por lo menos ubicada en el mismo lugar (nueva coincidencia entre Carvalho y su creador), a los personajes acompañantes, o la escolarización tanto del autor como de Carvalho en las monjas de S. Vicente de Paúl como se comenta en La soledad del manager (Vázquez Montalbán 45) y en la biografía de Vázquez Montalbán (Saval 2013 47), lo cual no estaba tan lejos de la realidad del novelista y poeta.

Volviendo al personaje de Carvalho, que como se ha dicho mantiene algunas coincidencias con el autor: origen, residencia, pasado, entre otras, acaba de perfilarse definitivamente en La soledad del manager, definiendo algunos aspectos que no había terminado de concretar en Tatuaje. Aparece en la serie de manera ya fija la receta carvalhiana, en este caso un Salmis de pato, además de la quema de libros, que ya apareciera en Yo maté a Kennedy. La clave del personaje, a mi modo de ver, y después de que Vázquez Montalbán negara repetidas veces la influencia de la novela de detectives norteamericana conocida como "hard-boiled novel" de los Hammett, Chandler, MacDonald o Cain, es su descripción cinematográfica. Como comentara Colmeiro con respecto a la novela policiaca española en la transición:

La novela policiaca negra se reveló como un auténtico descubrimiento para la gran mayoría de su nuevo público lector español -casi exclusivamente conocedor de la tradición cinematográfica de dicho género-compuesto en general de lectores no aficionados a la novela policiaca en sus anteriores modalidades y no diferenciado apreciablemente del público culto lector habitual de literatura sin adjetivación (Colmeiro 168). 
En La soledad del manager aparecen numerosas descripciones de algunos personajes con claras referencias al cine de Hollywood y su lectura de las novelas del sub-género del "hard-boiled novel", ademas de muchas otras, en un claro acercamiento a las referencias culturales de los posibles lectores. En la obra que nos ocupa, el coronel Parra le dice: "Me dijeron que eras detective privado, como en las novelas o las películas de Bogart" (Vázquez Montalbán 53). Más Adelante cuando unos policías le dicen: "no se crea usted el James Bond", contesta: "Me parezco más a Gregory Peck" (Vázquez Montalbán 63).

Cuando se refiere a si el personaje está preparado para soportar la tortura dice: "A Carvalho la peripecia le pareció una excelente secuencia de la película antialemana interpretada por James Cagney y Richard Conte, muy en la línea de 13 Rue Madeleine" (Vázquez Montalbán 43). Más adelante en su descripción del personaje del coronel Parra dice: "Quince años de distancia no habían aminorado su parecido real con Rosanno Brazzi ahora quizá más cercano al de Locuras de Verano que al de La corona de hierro (Vázquez Montalbán 52). Más adelante y aplicado a Pepe Carvalho, Vilaseca le comenta: "Usted seguro que podría hacer de asesino. Una especie de Richard Widmark a la española" (Vázquez Montalbán 77). Las descripciones mediante referencias a escenas cinematográficas abundan en el texto (Vázquez Montalbán 79, 80). Pero También aparece una descripción física de Carvalho por parte de Vilaseca: "Ha de cuidarse el pelo, caramba. Esas entradas. Yo estaba al borde de la calva y fui al médico a tiempo. ¿Sabe cuál es el problema? Nervioso. Vida doméstica. Consecuencia: calvo y gordo" (Vázquez Montalbán 79). ¿Quizas una de las preocupaciones del autor? ¿Quién sabe?

Definitivamente el cine hollywoodense de los años 40 y 50 jugará un papel clave en la serie, y en cierta medida Carvalho será leído y decodificado e interpretado por el lector del momento de esta manera: Un detective procedente de la gran pantalla en blanco y negro al que añadirá ciertas características intransferibles; entre otras la gastronomía y la quema de libros, pero también un pasado de agente de la Cía y exmiembro del partido comunista con experiencia carcelaria incluida. Definitivamente, Carvalho es heredero de esta tradición. En palabras de Harmut Stenzal: "Factor decisivo para el desarrollo de esta serie es el recurso a aquella tradición de crítica social propia de la novela policíaca que surgió y creció tras las huellas de la hardboiled novel" (Stenzal 258). Como se pregunta el detective barcelonés, nacido en El Raval, en La soledad del manager: 
Otro modelo de comportamiento a elegir. ¿A quién debo imitar? ¿A Bogart interpretando a Chandler? ¿A Alan Ladd en los personajes de Hammet? ¿Paul Newman en Harper? ¿Gene Hackman? En la soledad de su coche reptante por las laderas del Tibidabo. Carvalho asumía los tics de cada cual. La mirada húmeda de Bogart y el labio despectivo. La necesidad de Ladd a caminar lo más erguido posible para disimular su escasa estatura, de ahí esa cabecita rubia siempre punzante, como tratando de tirar del cuello. El autoconvencimiento de la propia belleza de Newman. El cansancio vital de un hombre con cuernos y más de cien kilos de peso en el personaje de Hackman (Vázquez Montalbán 95).

Bogart, Ladd, Newman, Hackman, todos parecen ser modelos del tipo de detective propuesto en la serie. Fabienne Viala ha comentado este aspecto en su estudio sobre la novela negra en Vázquez Montalbán y Didier Daeninckx:

Pepe, qu'on compare souvent à Humphrey Bogart sans l'imperméable!, à James Bond, ou encore à un "Richard Widmarck espagnol", se considère souvent comme le personage d'un film policier et prend parfois "le risqué de passer pour un detective de cinema" (Viala 61).

A modo de conclusión se puede constatar que La soledad del manager establece el formato definitivo de la serie Carvalho, que Vázquez Montalbán ya había venido perfilando desde sus artículos de la serie "El idiota en familia", retomando, sin duda las dos novelas anteriores de la serie Carvalho, haciendo uso de toda una gama de referentes autobiográficos así como cinematográficos, en este último caso compartido por su audiencia lectora, sobre la que se fundamentará el éxito de la serie y del personaje, creación de Vázquez Montalbán. Si Carvalho y Manuel Vázquez Montalbán se parecían, muy probablemente podríamos decir que no a pesar de toda una serie de interesantes y jugosas coincidencias. Compartieron ciertas vicisitudes históricas y coinciden en su localización y ubicación, pero este tema merece, quizás, un estudio mucho más amplio y de mayor profundidad.

\section{Bibliografía}

Aranda, Quim. Què pensa Manuel Vázquez Montalbán? Barcelona:

Dèria editors, 1995. Impreso. 
Balibrea, Mari Paz. En la tierra baldía. Manuel Vázquez Montalbán y la izquierda española en la postmodernidad. Mataró (Barcelona): El viejo topo, 1999. Impreso.

Camarasa, Paco. Prólogo a Carvalho: huidas de Manuel Vázquez Montalbán. Barcelona: Planeta, 2013. Impreso.

Colmeiro, José F. La novela policiaca española: Teoría e Historia crítica. Barcelona: Anthropos, 1994. Impreso.

Eaude, Michael. Con el muerto a cuestas: Vázquez Montalbán y Barcelona. Barcelona: Alrevés, 2011. Impreso.

Izquierdo, José María. "Manuel Vázquez Montalbán (1939-2003): El escriba y la ciudad democrática". Moderna språk, XCVIII, 1 (2004): 94-107. Impreso.

Salgado, Francesc. Editor e Introducción. Obra periodística. Volumen II: Del humor al desencanto (1974-1986) de Manuel Vázquez Montalbán. Barcelona: Debate, 2011. Impreso.

Saval, Josep Vicenç. "Biscuter era andorrà: els inicis de Manuel Vázquez Montalbán a Editorial Andorra". Portella, Andorra/Lletres/Arts, 8 (2014): 60-61.

---. Vázquez Montalbán, una biografía revisada. Barcelona: Alrevés, 2013. Impreso.

Stenzel, Hartmut. "Las novelas policíacas - Pepe Carvalho en busca de la identidad de la España posfranquista". Abriendo caminos. La literatura española desde 1975, Eds. Dieter Ingenschay y Hans-Jörg Neuschäfer (eds.). Barcelona: Lumen, 1994. 255-267. Impreso.

Tyras, Georges (2003). Geometrías de la memoria. Conversaciones con Manuel Vázquez Montalbán. Granada: Zoela ediciones, 2003. Impreso.

Vázquez Montalbán, Manuel. La soledad del manager. Barcelona: Planeta, 1990. Impreso.

Viala, Fabienne. Le Roman noir à l'encre de l'histoire: M. Vásquez Montalbán et Didier Daeninckx ou Le Polar en su tinta. Paris: L'Harmattan, 2006. Impreso. 